Article

\title{
Empirical Study on Temperature Influence on Noise Measurements with the Statistical Pass-By Method
}

\author{
Michiel Geluykens ${ }^{1, *(\mathbb{D}}$, Ablenya Grangeiro de Barros ${ }^{1}$ (D) Luc Goubert $^{2}$ and Cedric Vuye ${ }^{1}$ (D) \\ 1 EMIB Research Group, Faculty of Applied Engineering, University of Antwerp, 2020 Antwerp, Belgium; \\ ablenya.barros@uantwerpen.be (A.G.d.B.); cedric.vuye@uantwerpen.be (C.V.) \\ 2 Belgian Road Research Centre, Woluwedal 42, 1200 Brussels, Belgium; l.goubert@brrc.be \\ * Correspondence: michiel.geluykens@uantwerpen.be
}

Citation: Geluykens, M.; de Barros, A.G.; Goubert, L.; Vuye, C. Empirical Study on Temperature Influence on Noise Measurements with the Statistical Pass-By Method. Sustainability 2022, 14, 2099. https:// doi.org/10.3390/su14042099

Academic Editor: Guillermo Rey Gozalo

Received: 13 January 2022

Accepted: 10 February 2022

Published: 12 February 2022

Publisher's Note: MDPI stays neutral with regard to jurisdictional claims in published maps and institutional affiliations.

Copyright: (c) 2022 by the authors. Licensee MDPI, Basel, Switzerland. This article is an open access article distributed under the terms and conditions of the Creative Commons Attribution (CC BY) license (https:// creativecommons.org/licenses/by/ $4.0 /)$.

\begin{abstract}
Road traffic noise measurements, such as the Statistical Pass-By method (SPB) described in ISO 11819-1, are pivotal in assessing this noise pollution problem. As temperature is a primary cause of uncertainty in tyre/road noise measurements, the SPB method results need to be temperature corrected. The ISO 11819-1 standard is currently being revised and will refer to ISO/DTS 13471-2:2021, also in the drafting stage, for a temperature-correction procedure that is not present in the current ISO 11819-1:1997 version. Compared to other methods, little research has evaluated the temperature influence using the SPB method. In this paper, 18 SPB measurements were performed at three locations, with dense asphalt concrete and SMA as the pavement type. In total, over 5700 vehicles were captured, covering the complete temperature range in ISO 11819-1. For passenger cars, a temperature coefficient of $-0.103 \mathrm{~dB} /{ }^{\circ} \mathrm{C}$ was obtained while no statistically significant proof was found that temperature influences the sound-pressure levels for heavy vehicles at the speeds in this study (45-65 km/h). In this speed range for heavy vehicles, not only the tyre/road noise is a significant source of pass-by vehicle noise but also the power unit noise, on which the temperature influence is more complicated. Additionally, the analysis of various temperatures (air, road and estimated tyre temperature) revealed that the air temperature appears to be best suited for the temperature correction procedure. In third-octave bands, no effect was observed in the low-frequency range for passenger cars, contradicting previous research. Negative correction coefficients were found in the middle and high-frequency range, although trends presented in other studies were not observed.
\end{abstract}

Keywords: SPB; temperature correction; passenger cars; heavy traffic; frequency spectra

\section{Introduction}

Noise features one of the major environmental risks to human health, with road traffic noise being the most common source of community noise in urban areas [1]. The systematic reviews that endorsed the update of World Health Organization's (WHO) Environmental Noise Guidelines in 2018 [2] point out moderate- to high-quality evidence of correlations between exposure to environmental noise and several health complications. Road traffic noise specifically is linked to the incidence of ischemic heart diseases [3], cortical awakenings and self-reported sleep disturbance [4] and emotional and conduct disorders in children [5], among others. Besides human well-being, traffic noise also affects wildlife [6]. The continuing urbanisation and growing population, especially in densely built-up areas, increase exposure to road traffic noise. Even though measures as a modal shift to railway, pedestrian and bike traffic have been supported, the EU Reference Scenario 2016 predicts for the time horizon of 2050 that road transport is expected to maintain its dominant role, especially for passenger transport [7].

In order to mitigate the impacts entailed by road-traffic-noise exposure, there must first be a solid base for assessing road traffic noise. Various standards and regulations are already in place for this purpose. The United Nations Economic Commission for Europe 
(UNECE) regulation R.117 [8] contains requirements for noise emissions by tyres and uses the same coast-by measurement principle as found in ISO 13325:2019 [9]; ISO 11819-2:2017 describes the Close ProXimity method (CPX) [10]; ISO 11819-1 defines the Statistical Pass-By method (SPB) [11]; and the On-Board Sound Intensity method is described in [12].

It is generally accepted that road traffic noise decreases with increasing temperature in the case of asphalt pavements, with A-weighted noise levels dropping by up to $1 \mathrm{~dB}$ each $10{ }^{\circ} \mathrm{C}$ increase in air temperature for dense asphalts [13]. Additionally, this effect is larger for passenger cars compared to trucks [14]. Even though there are already standardised procedures for temperature correction, the extent to which temperature affects the measured noise levels is still unclear, especially for SPB. As road traffic noise results from multiple noise-generating mechanisms, the effect of single parameters, such as temperature, is complex to assess. The generation mechanisms are generally categorised under power-unit noise, aerodynamic noise, and tyre/road noise $[14,15]$. Power-unit noise is the mechanical and combustion noise associated with vehicle propulsion; aerodynamic noise results from the turbulent airflow around the body (at higher speeds). Lastly, the tyre/road noise is generated by the interaction between the tyre and the road at the pavement surface. Tyre/road noise itself is a convoluted combination of various generation and amplification mechanisms that result in noise in different, and often overlapping, frequency ranges $[15,16]$.

Temperature affects the different components of tyre/road noise to various extents. Still, this influence is mostly attributed to the softening of the tyre rubber with increasing temperatures, increasing the damping of vibrations that would otherwise result in noise [17]. While the temperature increase decreases the stiffness of the pavement, its effect on noise reductions is only noticeable if the tyre and pavement stiffness are in the same order of magnitude (pavement stiffness/tyre stiffness < 10) [18]. For conventional hot asphalt mixtures and in the typical temperature range achieved in the field, high temperatures cannot reduce the pavement stiffness to values comparable to the stiffness of a rubber tyre. This effect only becomes prominent if alternative materials, such as crumb rubber substituting mineral aggregate, are used to increase the asphalt elasticity [19]. In ISO 11819-1:1997 [11], tyre/road noise is assumed to be dominant at speeds above $45 \mathrm{~km} / \mathrm{h}$ and the effect of temperature on power unit noise and aerodynamic noise is negligible. The influence of temperature on the noise propagation towards the environment within the scope of ISO 11819-1:1997 also appears to be insignificant.

As temperature influences emitted road-traffic noise, there is a common need for temperature correction among regulations and standardised methods in order to achieve accurate assessment tools. Among the road traffic noise measurement methods mentioned before, the SPB (ISO 11819-1:1997 [11]) is the only one that does not describe a temperature correction. However, this standard is currently under revision [20]. The new version will refer to a separate standard for a temperature correction applicable to measurements with pass-by methods, the ISO/DTS 13471-2:2021, which is currently also in the draft stage [21]. In this document, the sound-pressure levels, either overall sound-pressure levels (SPL) or divided into one-third octave bands, are corrected to the reference temperature of $20^{\circ} \mathrm{C}$ by semi-generic temperature coefficients based on pavement type, vehicle class and speed.

The existing research on temperature influence on road-traffic noise levels focuses mostly on CPX [13,22,23], and literature is hardly available for the SPB method. Moreover, considering the limited transferability from one method to another, this study aims to fill this gap. We constructed temperature corrections based on a large dataset collected by the authors and compared them to the coefficients proposed in ISO/DTS 13471-2:2021 and literature. This dataset was particularly composed of large numbers of heavy vehicles, shedding light into the temperature-SPL relation for this vehicle category. Additionally, even though the ISO/DTS 13471-2:2021 proposes a single correction coefficient for all frequency bands in the spectrum, we investigated the frequency dependence of this parameter, as already suggested in previous studies $[13,17,24]$. Lastly, these analyses have all been performed for three different temperatures (air, road and estimated tyre temperature), as 
the literature points out the importance of the physical media in assessing temperature coefficients $[23,24]$.

The structure of this paper is organised as follows: in Section 2, the overall research goals, research methodology, methods and selected test locations are described in more detail. The results are presented and discussed in Section 3. The paper ends with a summary of the main conclusions, limitations and suggestions for further research.

\section{Materials and Methods}

\subsection{Research Methodology}

The main goal of this study is to construct a temperature correction for the different vehicles categories based on the SPB method and compare the results with the suggested temperature coefficients from the draft standard [21]. Secondly, the use of different temperatures (air, road and estimated tyre temperature) for temperature correction was compared. For this purpose, we did not perform one-day SPB measurements at many locations. Instead, we repeated the SPB measurements on multiple days over the entire temperature range of ISO/DIS 11819 at three different locations, limited to dense asphalt pavement types. Furthermore, for the passenger car vehicles, the use of different temperatures (air, road and estimated tyre temperature) for temperature correction was compared and an analysis was made of the temperature coefficients in one-third octave bands. Due to the limited available data for one-third octave bands, this last analysis was only performed for the P category at a single location. This study applied two different measurement methods to the three test locations, as shown in Figure 1.

\section{Research goal: Temperature influence on road traffic noise}

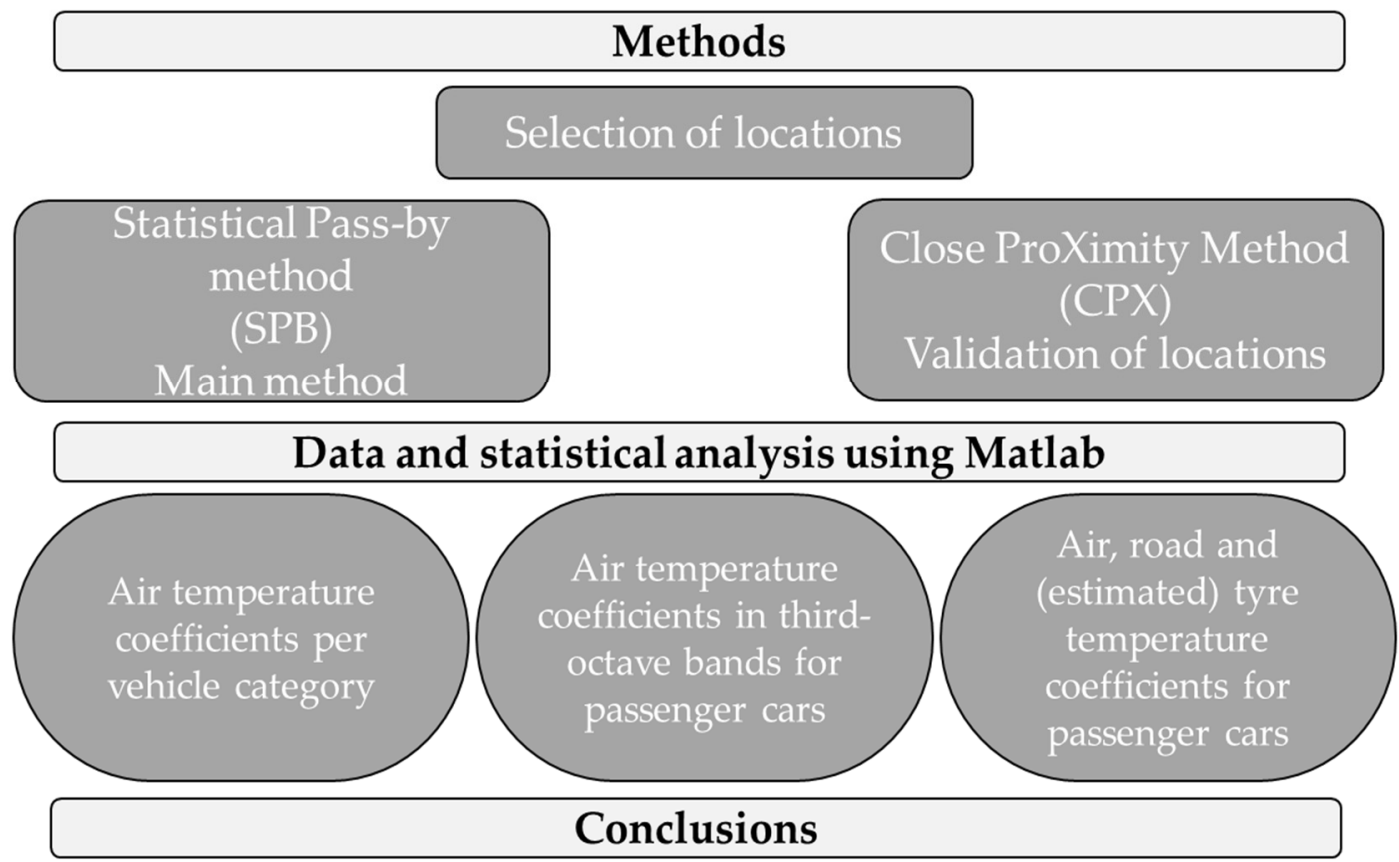

Figure 1. Graphical overview of this study.

\subsection{Test Locations}

The test locations were selected based on some pre-defined requirements: for safety reasons, the streets should have a maximum speed limit of $70 \mathrm{~km} / \mathrm{h}$; pavement surface must be in a moderate to good condition; dense asphalt pavement as asphalt type; and compliance with the ISO 11819-1 standard. Additionally, as literature on temperature influence on sound pressure levels of heavy vehicles is limited, locations with a large share 
of heavy traffic were selected. Potential sites were firstly selected using Google Streetview. After on-site checks, three locations were chosen in the Antwerp region (Belgium). A detailed description of the locations is presented in Table 1. The complete acoustic free field around the microphone as described in the ISO 11819-1 standard proved very difficult to achieve and perfect compliance of all locations was impossible; remarks on minor deviations from the free-field condition are also included in Table 1.

Table 1. Overview of measurement locations.

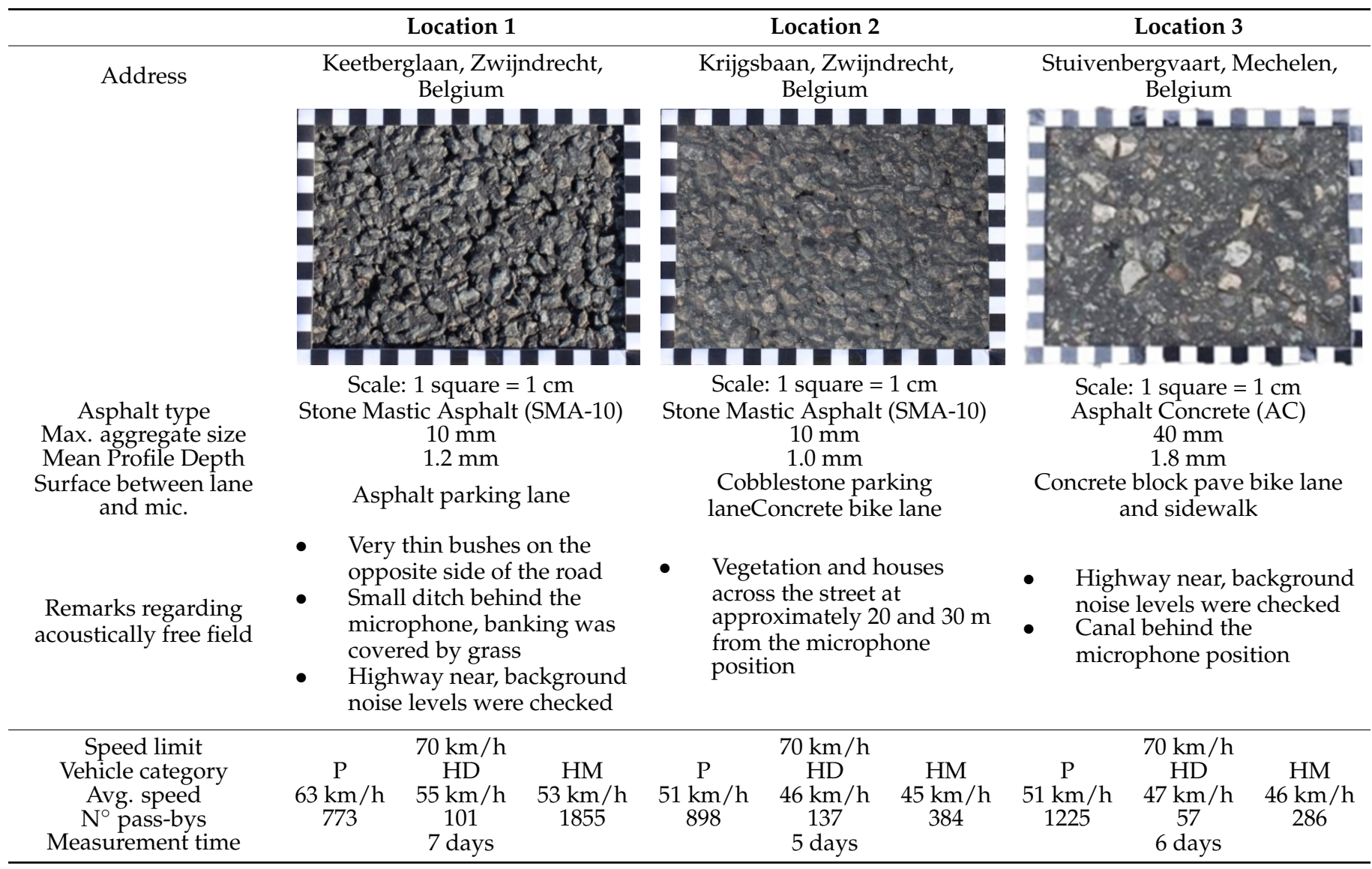

\subsection{Measurement Methods}

\subsubsection{Statistical Pass-By}

The ISO 11819-1 standard describes the SPB method and is currently under revision. Although it is still subject to changes, the updated version is described in ISO/DIS 11819-1 [20]. The purpose of this document is to provide a standardised method for evaluating the influence of different road surfaces with regard to road traffic noise. Other methods such as CPX and OBSI focus on the tyre/road noise close to the source, while the SPB method is based on the overall vehicle noise in free-flow traffic conditions and is measured at the roadside, and thus is more representative of the impact of the pavement on road traffic noise in the environment. In more detail, the maximum A-weighted sound pressure level $\left(L_{\mathrm{A}, \max }\right)$ and speed $(v)$ of a statistically significant number of vehicles are measured together with some relevant environmental parameters (wind speed and temperatures), see Figure 1. Each passing vehicle (pass-by) is assigned to one of the vehicle categories: passenger cars (P), dual-axle heavy vehicles (HD) and multiple-axle heavy vehicles (HM). The vehicle category allocation is based on vehicle weight, tyre type and number of axles. This study used the updated requirements for the vehicle categories in ISO/DIS 11819-1 [21]. If the pass-by does not fit the description of any of the vehicle categories, or any of the other requirements as described in the standard, it is discarded. The relation between $L_{\mathrm{A}, \max }$ and 
$v$ is determined and used to calculate the Statistical Pass-By Index, a parameter suitable for comparing the acoustic performance of different road surfaces.

In this study, 18 days of SPB measurements were performed according to ISO/DIS 11819-1 [20] using a single microphone set up at $1.2 \mathrm{~m}$ height. To create a robust dataset, the measurements were repeated several times at the three locations. The study ranged over a 7-month period, from February to August 2021, resulting in a large temperature range while also improving the sample size for the statistical analysis. One concern related to the relatively long timeframe of this measurement campaign would be some extent of acoustic ageing. Even though we could not perform repeated CPX measurements due to budget constraints, we concluded by visual inspections of the road surface that no noticeable ravelling or other distresses developed over this period. Additionally, based on an ageing coefficient of $0.4 \mathrm{~dB}$ /year obtained by [25] with methods and pavement types comparable to the ones in this study, a $0.23 \mathrm{~dB}$ increase in noise levels is estimated from the beginning to the end of the measurement campaign. This increase would have little impact the temperature coefficients.

The Belgian Road Research Centre (BRRC) provided the used SPB equipment that consisted of a sonometer type 2260 by Brüel and Kjaer and a speed radar KR-10 SP. The sonometer and radar were connected to a laptop with dedicated software to capture passbys' $L_{\mathrm{A}, \max }$ and speed. However, this software could only register the overall $L_{\mathrm{A}, \max }$. For this reason, a second sonometer, NTi XL2, was set up in parallel to capture the $L_{\mathrm{A}, \max }$ in one-third octave bands. Round robin tests were performed to assure the conformity of overall $L_{\mathrm{A}, \max }$ of both sonometers. A schematic overview of the equipment and a photo taken during one of the measurements is presented in Figure 2.

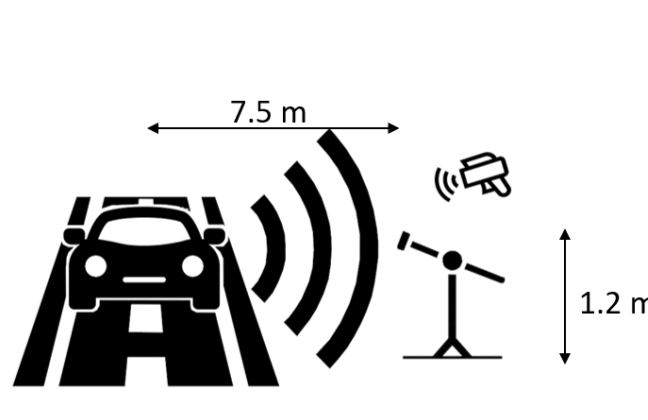

(a)

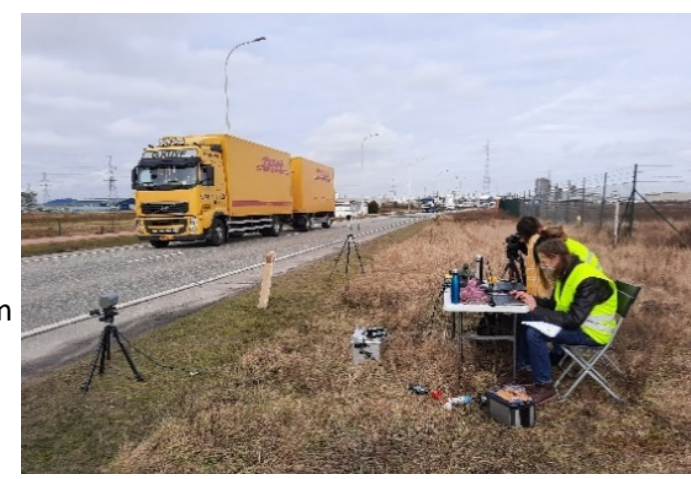

(b)

Figure 2. SPB method set up. (a) scheme; (b) during a measurement.

\subsubsection{Close ProXimity Method (CPX)}

In addition to the SPB method, CPX measurements were performed by the Belgian Road Research Centre (BRRC) at the three sites to check if the pavement section in front of the microphone was representative of the road. In this method, a trailer containing a reference tyre and a microphone setup is towed by a vehicle. The enclosure on the trailer shields noises from the surroundings to ensure that only tyre/road noise is captured. The measurements were performed in accordance with ISO 11819-2 [10]. The inner microphone setup was used in a trailer by $\mathrm{M}+\mathrm{P}$, with the Standard Reference Test Tyre (SRTT), to measure a section of $200 \mathrm{~m}$ centered around the microphone position of the SPB measurements. The air temperature during the measurements was ideal, at $20 \pm 2{ }^{\circ} \mathrm{C}$.

\subsection{Temperature}

To correct $L_{\mathrm{A}, \max }$ for temperature, the ISO/DTS 13471-2 [21] standard proposes the correction of the individual pass-bys to the reference temperature of $20^{\circ} \mathrm{C}$, using Equation (1):

$$
L_{\mathrm{A}, \max \left(20{ }^{\circ} \mathrm{C}\right)}=L_{\mathrm{A}, \max (T)}-\gamma_{\mathrm{U}}\left(T-20^{\circ} \mathrm{C}\right)
$$


where $L_{\mathrm{A}, \max \left(20^{\circ} \mathrm{C}\right)}$ is the maximum A-weighted sound pressure level corrected to the reference temperature of $20^{\circ} \mathrm{C}, L_{\mathrm{A}, \max (T)}$ is the uncorrected maximum A-weighted sound pressure level, $T$ is the air temperature at the moment of the pass-by in ${ }^{\circ} \mathrm{C}$, and $\gamma_{\mathrm{U}}$ is the temperature coefficient for overall vehicle noise, further calculated by Equation (2):

$$
\gamma_{U}=W_{U} \gamma_{t}
$$

where $\gamma_{t}$ is the temperature coefficient for tyre/road noise based on vehicle class and speed, and $W_{U}$ is a reducing factor to account for the diluting effect of power unit noise. The standard requires the use of the air temperature, yet it is argued that the road surface and tyre temperature could also be appropriate for this correction $[23,24]$. Tyre temperature appears to be best suited as it is most closely related to the temperature mechanisms. Due to the nature of the SPB measurements, it is impossible to gather tyre temperature data for the passing vehicles. Both air and road temperature directly affect the tyre temperature by convection and conduction, respectively, therefore, affecting noise-generation mechanisms indirectly. Air temperature is most prevalent in standardised measurement methods because of practicality and safety [26]. Additionally, the air temperature is more stable. In this study, both road-surface temperature and ambient air temperature were captured every $15 \mathrm{~min}$ to an accuracy of $0.1^{\circ} \mathrm{C}$. In addition, Equation (3) by Erik Bühmann et al. [23] for estimating the tyre temperature was used to check if this could improve the statistical significance of the obtained temperature corrections.

$$
T_{\text {tyre }}=0.50 \cdot T_{\text {road }}+0.44 \cdot T_{\text {air }}+6.7
$$

In order to establish the influence of temperature, a simple linear regression between recorded $L_{\mathrm{A} \text {,max }}$ and temperature would not suffice, as the spread of data inherent to the SPB method results in significant uncertainties. Thus, a procedure for the data analysis was applied using Matlab, described as follows:

1. For each vehicle category, the pass-bys were grouped based on the temperature during their passage: the temperature range obtained in the measurements for each location was divided into 14 different ways (starting from steps of $1^{\circ} \mathrm{C}$, increasing the step size by $0.5^{\circ} \mathrm{C}$ up to $10^{\circ} \mathrm{C}$ steps), and the pass-bys were assigned to these temperature groups. The smaller the step, the more consistent the $L_{\mathrm{A}, \mathrm{max}}$-temperature relation, but the smaller the group size. Thus, the optimum temperature step was chosen as the smallest as possible that resulted in the maximum number of groups containing 30 or more pass-bys, for statistical relevance;

2. The $L_{\mathrm{A}, \max }$ of the pass-bys within the temperature groups was still affected by speed. To normalise for speed, the average $L_{\mathrm{A} \text {,max }}$ per temperature group was corrected to a reference speed, which was the average speed of all pass-bys of that vehicle category. This correction uses the speed coefficient, which is the slope $b$ of the regression line of $L_{\mathrm{A} \text {,max }}$ versus the logarithm of speed for all pass-bys of that vehicle category, independent of temperature. See Equation (4);

$$
\text { Group } L_{\mathrm{A}, \text { max,speed corrected }}=\text { Group } L_{\mathrm{A}, \text { max,average }}-b \cdot \log _{10}\left(\frac{\text { Group speed average }}{\text { Overall speed average }}\right)
$$

3. Lastly, a linear regression was applied to the speed corrected average $L_{\mathrm{A}, \max }$ of the temperature groups versus the temperature of the groups. The slope of this regression line represents the temperature coefficient, equivalent to the temperature coefficient for overall vehicle noise $\gamma_{\mathrm{U}}$, in ISO/DTS 13471-2 [21].

Steps 1 and 2 were introduced to reduce the spread of data inherent to the SPB method and increase the accuracy of the linear regression. As part of this procedure, the data within each temperature group were reduced to a single value, the Group $L_{\mathrm{A} \text {,max,speed corrected }}$ as presented in Equation (4); these values are assumed to represent the average vehicle within the temperature category. To ensure that this is statistically sound, a number of 30 pass-bys was chosen as the minimum sample size to calculate Group $L_{\mathrm{A} \text {,max,speed corrected }}$. 
Figure 3 shows a diagram of $L_{\mathrm{A}, \max }$ versus temperature to illustrate the procedure above described, with the data for passenger cars at location 2 . The black dots represent each individual pass-by; a large spread is clearly visible. The green vertical lines are the borders of the temperature groups. The speed-corrected average $L_{\mathrm{A} \text {,max }}$ for the temperature groups with 30 or more pass-bys is given by the red markers, while the slope of the regression line, in red, corresponds to $\gamma_{U}$. The temperature coefficient $\gamma_{U}$, as well as the $p$-value and $\mathrm{R}^{2}$ were calculated for the different vehicle categories and temperature types at all three locations individually.

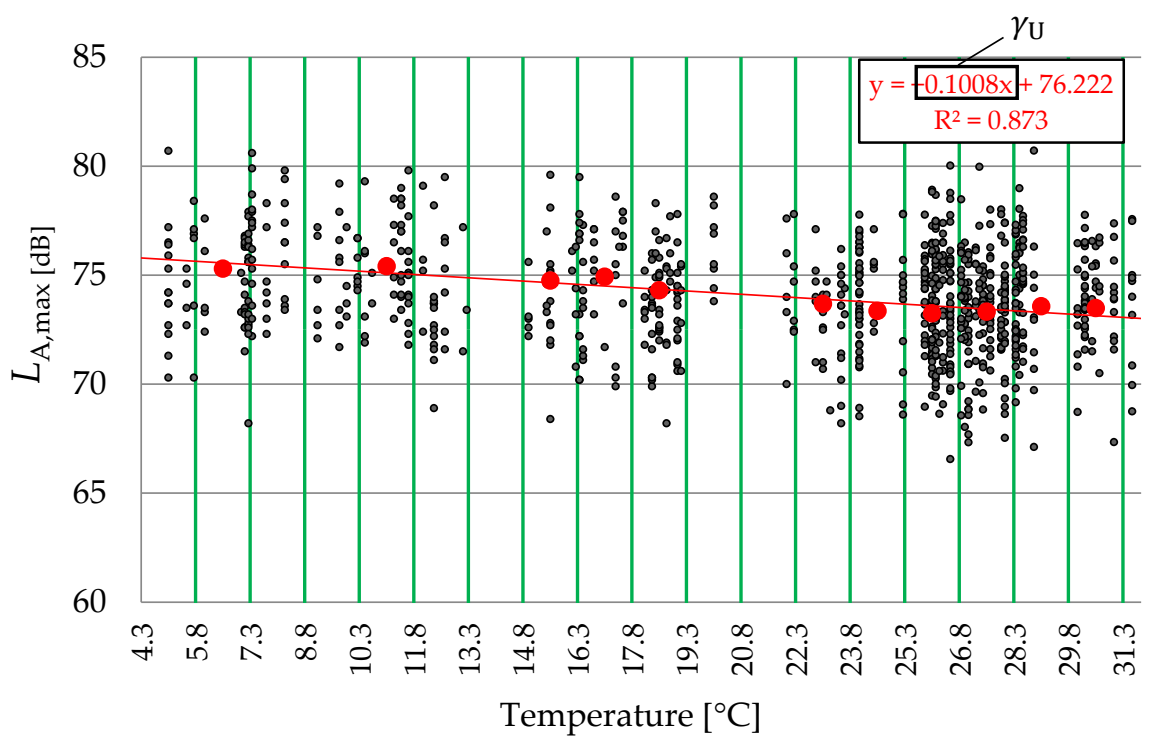

Figure 3. Procedure to calculate the temperature coefficient $\gamma_{U}$ visualised using data of vehicle category $\mathrm{P}$ at location 2.

\section{Results and Discussion}

An overview of the temperature coefficients for overall $L_{\mathrm{A} \text {,max }}$ obtained for the three different vehicles categories is presented in Table 2 at all locations and for the three different temperature types. The coefficients of determination $\left(\mathrm{R}^{2}\right)$ and Standard Error (SE) are included as well. First, these results will be discussed for the vehicle category "passenger cars" (P) and "heavy vehicles" (HD and HM). Next, based on the $\mathrm{R}^{2}$, the optimal temperature for correction will be evaluated. In addition to the temperature coefficients for overall $L_{\mathrm{A} \text {,max }}$, the temperature influence has also been studied in third-octave bands, covered in the fourth subsection of this section. A brief discussion of the CPX measurement results concludes this section.

\subsection{Temperature Correction Based on SPB Results}

\subsubsection{Passenger Cars}

In the case of passenger cars, the calculated temperature coefficient for overall $L_{\mathrm{A}, \max }$ ranges from -0.099 to $-0.108 \mathrm{~dB} /{ }^{\circ} \mathrm{C}$ with an $\mathrm{R}^{2}$ of 0.84 to 0.90 . Figure 4 presents the air-temperature-based correction coefficients for the different vehicle categories graphically. The results are similar for the SMA and asphalt concrete types, leading to an average value of $-0.103 \mathrm{~dB} /{ }^{\circ} \mathrm{C}$. An overview of correction procedures in other standards is found in Table 3, based on [23].

The result for passenger cars is close to the corrections proposed in the ISO standards, where $-0.09 \mathrm{~dB} /{ }^{\circ} \mathrm{C}$ is proposed for the SPB method in ISO/DTS 13471-2 [21], and $-0.110 \mathrm{~dB} /{ }^{\circ} \mathrm{C}$ for the $\mathrm{CPX}$ method [27]. The temperature coefficient is slightly larger compared to ISO/DTS 13471-2, but the differences between the findings in this study are small as they are limited to $0.013 \mathrm{~dB} /{ }^{\circ} \mathrm{C}$. Over a temperature range of $30{ }^{\circ} \mathrm{C}$ (e.g., the $5-35{ }^{\circ} \mathrm{C}$ range proposed in the standard), this would lead to only a $0.39 \mathrm{~dB}$ difference in corrected $L_{\mathrm{A} \text {,max }}$. Therefore, the coefficients obtained in this study are in line with the procedure in 
ISO/DTS 13471-2. The temperature coefficients for the UNECE R.117 and OBSI (AASHTO T 360: 2016) are notably smaller than those found in this study and the ISO standards. UNECE R.117 contains the only procedure that relies on road temperature. It applies a segmented-linear correction procedure with a temperature coefficient of $-0.06 \mathrm{~dB} /{ }^{\circ} \mathrm{C}$ from 5 to $20^{\circ} \mathrm{C}$ and $-0.03 \mathrm{~dB} /{ }^{\circ} \mathrm{C}$ from 20 to $50{ }^{\circ} \mathrm{C}$ road temperature [8]. The road temperature coefficients for passenger cars in this study ranged from -0.071 to $-0.093 \mathrm{~dB} /{ }^{\circ} \mathrm{C}$, with an average of $-0.079 \mathrm{~dB} /{ }^{\circ} \mathrm{C}$, and no indication of a segmented linear temperature influence. There are major differences in these temperature coefficients compared to UNECE R.117, especially at road temperatures above $20^{\circ} \mathrm{C}$ : the findings from this study are more than twice as large. Even though the Coast-By method described in UNECE R.117 is comparable to that used in this study, the tested pavement types differ. While in UNECE R.117 an ISO test track is prescribed, we investigated asphalt concrete and SMA pavements. The discrepant temperature coefficients may therefore be attributed to the different acoustic properties of the evaluated pavements.

Table 2. Temperature coefficients for all vehicle categories at all three locations.

\begin{tabular}{|c|c|c|c|c|c|c|c|c|c|c|c|c|}
\hline & $\gamma_{\mathrm{U}, \mathrm{air}}$ & $\mathbf{R}^{2}$ & SE & $\begin{array}{c}p- \\
\text { Value }\end{array}$ & $\gamma_{\mathrm{U}, \mathrm{road}}$ & $\mathbf{R}^{2}$ & SE & $\begin{array}{c}p- \\
\text { Value }\end{array}$ & $\gamma_{U, \text { tyre }}$ & $\mathbf{R}^{2}$ & SE & $\begin{array}{c}p- \\
\text { Value }\end{array}$ \\
\hline \multicolumn{13}{|l|}{$\mathrm{P}$} \\
\hline Location 1 & -0.108 & 0.895 & 0.012 & $<0.001$ & -0.073 & 0.830 & 0.011 & $<0.001$ & -0.078 & 0.708 & 0.016 & $<0.001$ \\
\hline Location 2 & -0.101 & 0.873 & 0.013 & $<0.001$ & -0.071 & 0.740 & 0.011 & $<0.001$ & -0.090 & 0.827 & 0.012 & $<0.001$ \\
\hline Location 3 & -0.099 & 0.836 & 0.012 & $<0.001$ & -0.093 & 0.838 & 0.011 & $<0.001$ & -0.093 & 0.822 & 0.012 & $<0.001$ \\
\hline Average & -0.103 & 0.868 & 0.012 & - & -0.079 & 0.802 & 0.011 & - & -0.087 & 0.786 & 0.013 & - \\
\hline \multicolumn{13}{|l|}{ HM } \\
\hline Location 1 & $0.007^{1}$ & 0.039 & 0.009 & n.s. & $0.007^{1}$ & 0.046 & 0.007 & n.s. & $0.005^{1}$ & 0.043 & 0.006 & n.s. \\
\hline Location 2 & -0.004 & 0.015 & 0.018 & n.s. & -0.007 & 0.095 & 0.008 & n.s. & -0.008 & 0.095 & 0.011 & n.s. \\
\hline Location 3 & -0.034 & 0.500 & 0.015 & n.s. & -0.020 & 0.347 & 0.014 & n.s. & -0.013 & 0.121 & 0.018 & n.s. \\
\hline Average & -0.010 & 0.184 & 0.014 & - & -0.006 & 0.163 & 0.010 & - & -0.005 & 0.086 & 0.011 & - \\
\hline \multicolumn{13}{|l|}{$\mathrm{HD}^{2}$} \\
\hline Location 1 & -0.026 & 0.228 & 0.034 & n.s. & -0.022 & 0.302 & 0.019 & n.s. & -0.023 & 0.256 & 0.022 & n.s. \\
\hline Location 2 & -0.022 & 0.114 & 0.030 & n.s. & $0.010^{1}$ & 0.031 & 0.028 & n.s. & $<0.001^{1}$ & $<0.001$ & 0.024 & n.s. \\
\hline Average & -0.024 & 0.171 & 0.032 & - & -0.006 & 0.167 & 0.024 & - & -0.011 & 0.128 & 0.023 & - \\
\hline
\end{tabular}

n.s. = not significant at a $5 \%$ significance level. ${ }^{1} \mathrm{~A}$ few results among the heavy vehicles presented positive temperature coefficients. These results are not realistic. ${ }^{2}$ Vehicle category HD did not have sufficient data for the analysis at location 3 .

$\gamma_{\mathrm{U}}\left[\mathrm{dB} /{ }^{\circ} \mathrm{C}\right]$

0.02
0.01
0.00
-0.01
-0.02
-0.03
-0.04
-0.05
-0.06
-0.07
-0.08
-0.09
-0.10
-0.11
-0.12
-0.13

$-0.13$
Vehicle category

$\mathrm{HM}$

HD

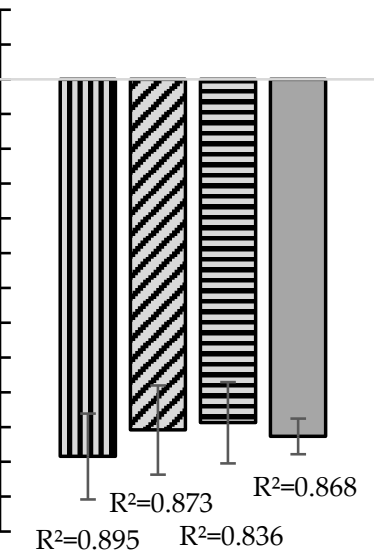

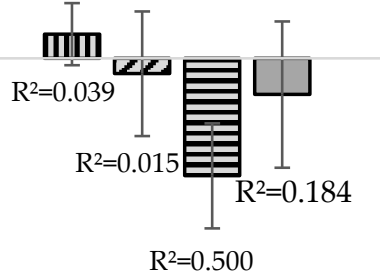

m Location 1

日Location 3

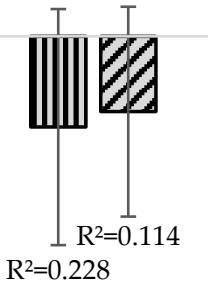

Location 2

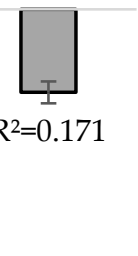

Figure 4. Temperature coefficients $\gamma_{U}$ for different vehicle categories and locations. 
Table 3. Temperature coefficients in different standards and regulations, based on [23] and adapted to the situation of this study.

\begin{tabular}{|c|c|c|c|c|c|c|c|c|}
\hline \multicolumn{2}{|c|}{ Standard/Regulation } & Method & \multicolumn{2}{|c|}{ Temp. Used } & Tyre/Vehicle & \multicolumn{2}{|c|}{ Pavement Type } & Temp. Coefficient \\
\hline \multicolumn{2}{|c|}{ UNECE R. 117 [8] } & Coast-by & \multicolumn{2}{|c|}{ Road } & $\begin{array}{c}\mathrm{C} 1(=\mathrm{P}) \\
\mathrm{C} 3(=\mathrm{HD} \text { and } \mathrm{HM})\end{array}$ & \multicolumn{2}{|r|}{ ISO 10844} & $\begin{array}{c}5-20{ }^{\circ} \mathrm{C}:-0.06 \\
20-50{ }^{\circ} \mathrm{C}:-0.03 \\
-\end{array}$ \\
\hline \multicolumn{2}{|c|}{ ISO/TS 13471-1 [27] } & \multicolumn{2}{|l|}{ CPX } & Air & $\begin{array}{l}\text { SRTT and AVON } \\
\text { AV4 }\end{array}$ & \multicolumn{2}{|c|}{ Dense asphalt } & $-0.14+0.0006 v$ \\
\hline \multicolumn{2}{|c|}{ ISO/DTS 13471-2 [21] } & \multicolumn{2}{|c|}{ SPB and others } & Air & $\begin{array}{c}\mathrm{C} 1(=\mathrm{P}) \text { and } \mathrm{C} 2 \\
\mathrm{C} 3(=\mathrm{HD} \text { and } \mathrm{HM})\end{array}$ & \multicolumn{2}{|c|}{ Dense asphalt } & $\begin{array}{l}-0.10^{1} \\
-0.06^{1}\end{array}$ \\
\hline \multicolumn{2}{|c|}{ AASHTO T 360-2016 [12] } & \multicolumn{2}{|c|}{ OBSI } & Air & SRTT & \multicolumn{2}{|r|}{ All } & -0.072 \\
\hline & & \multicolumn{7}{|c|}{$\begin{array}{l}\text { While there is extensive research on the temperature influence on road traffic noise } \\
\text { for passenger cars using the CPX method, only a few studies have used pass-by methods. } \\
\text { Table } 4 \text { summarises the temperature coefficients from these publications, retrieved from the } \\
\text { most similar conditions to this study. Information on pavement type and measurement } \\
\text { speed as presented in Table } 4 \text { is important as the effect of temperature on tyre/road noise } \\
\text { depends on air-void content, texture and tyre type [22], and with an increase in speed the } \\
\text { temperature influence decreases [28]. } \\
\text { Table } 4 \text {. Summary of temperature coefficients for passenger cars, calculated based on pass-by } \\
\text { methods as found in the literature. }\end{array}$} \\
\hline Publication & $\begin{array}{c}\gamma_{\mathrm{U}, \mathrm{air}} \\
{\left[\mathrm{dB} /{ }^{\circ} \mathrm{C}\right]}\end{array}$ & $\mathbf{R}^{2}$ air & Method & $\begin{array}{c}\text { Temp. } \\
\text { Range } \\
\text { Air/Road }\end{array}$ & $\begin{array}{l}\text { Pavement } \\
\text { Type }\end{array}$ & $\begin{array}{l}\text { Speed } \\
{[\mathrm{km} / \mathrm{h}]}\end{array}$ & & mment(s) \\
\hline $\begin{array}{l}\text { Sánchez- } \\
\text { Fernández } \\
\text { et al. [24] }\end{array}$ & -0.161 & 0.66 & $\begin{array}{l}\text { Continuous } \\
\text { Flow }\end{array}$ & $22-32 / 27-53$ & DAC & 100 & $\begin{array}{l}\text { - } \quad \text { Differ } \\
\text { used } t \\
\text { compc } \\
\text { which } \\
\text { uncer }\end{array}$ & $\begin{array}{l}\text { procedures were } \\
\text { correct for traffic } \\
\text { ition and flow, } \\
\text { tay increase } \\
\text { nty in the results }\end{array}$ \\
\hline $\begin{array}{l}\text { Jabben } \\
\text { et al. [29] }\end{array}$ & -0.05 & / & SPB & $-6-19$ & DAC & 60 & $\begin{array}{ll}\text { - } & \text { Perfor } \\
\text { - } & \text { Quest }\end{array}$ & $\begin{array}{l}\text { d during the night } \\
\text { able methodology }\end{array}$ \\
\hline $\begin{array}{l}\text { Landsberger } \\
\text { et al. [30] }\end{array}$ & -0.027 & poor & Coast-by & $5-35$ & $\begin{array}{c}\mathrm{ISO} \\
10844\end{array}$ & $53-80$ & $\begin{array}{l}\text { - } \quad \text { Avera } \\
\text { showe }\end{array}$ & $\begin{array}{l}\text { of } 6 \text { tyres that } \\
\text { poor correlation }\end{array}$ \\
\hline $\begin{array}{l}\text { Anfosso- } \\
\text { Ledée } \\
\text { et al. [17] }\end{array}$ & -0.10 & 0.86 & $\mathrm{CPB}$ & $0-30 / 0-50$ & DAC & 90 & - $\quad$ Two ty & es tested \\
\hline U.S.DoT [31] & -0.05 & / & $\begin{array}{l}\text { Continuous } \\
\text { flow and } \\
\text { SPB, both } \\
\text { at } 15 \mathrm{~m}\end{array}$ & / & DAC & & $\begin{array}{l}\text { - } \quad \text { Greate } \\
\text { test la } \\
\text { - } \quad \text { Calcu } \\
\text { differe } \\
\text { coeffic } \\
\text { showe }\end{array}$ & $\begin{array}{l}\text { distance between } \\
\text { and microphone } \\
\text { ed as the average of } \\
\text { temperature } \\
\text { nts of which some } \\
\text { a low } \mathrm{R}^{2}\end{array}$ \\
\hline $\begin{array}{l}\text { Yuan } \\
\text { et al. [32] }\end{array}$ & -0.079 & / & $\mathrm{CPB}$ & $1-33 / 5-55$ & $\begin{array}{l}\text { Dense } \\
\text { asphalt }\end{array}$ & 60 & $\begin{array}{r}\text { - } \quad \text { Tyres } \\
\text { show } \\
\text { tread. }\end{array}$ & $\begin{array}{l}\text { ed in the study } \\
\text { very aggressive }\end{array}$ \\
\hline
\end{tabular}


The coefficients in Table 4 vary greatly $\left(-0.027\right.$ to $\left.-0.161 \mathrm{~dB} /{ }^{\circ} \mathrm{C}\right)$, with an average equal to $-0.078 \mathrm{~dB} /{ }^{\circ} \mathrm{C}$. The temperature coefficients reported in this study are in the same range as those from the literature but are approximately $24 \%$ larger. This difference may be due to differences in methodology. Additionally, a lot of essential information relevant for the comparison is missing, such as the $\mathrm{R}^{2}$, or another concerning comment can be made. Among the publications presented in Table 4, only the study of Ref. [29] used the SPB method and reported a temperature coefficient of $-0.05 \mathrm{~dB} /{ }^{\circ} \mathrm{C}$, which is significantly smaller. However, the data from Ref. [29] were gathered during the night. As the pavement is not heated by solar irradiation, the relation between $L_{\mathrm{A}, \max }$ and temperature may not be the same as during the day.

\subsubsection{Heavy Vehicles}

As presented in Table 2, the findings for heavy vehicles are notably different from those of passenger cars. Neither the HD nor HM categories presented $p$-values over 0.05, showing no statistically significant proof of a temperature influence. Although the result from location 3 for HM gives a remarkably higher $\mathrm{R}^{2}$ and temperature coefficient closer to that proposed in the standard, this result may be attributed to the smaller sample size, as it contained considerably fewer HM pass-bys than the other locations (286 compared to 1855 for location 1). As a test, the analysis was repeated with random samples of the same size taken from location 1, which had the most HM pass-bys. This smaller size resulted in a wide range of $R^{2}$ values, some larger than the $R^{2}$ reported for location 3 , indicating that the $\mathrm{R}^{2}$ of location 3 does not imply a more accurate result. As a final attempt at achieving a temperature correction for the heavy vehicle categories, the data from all locations were speed corrected and then combined. A linear regression on $L_{\mathrm{A}, \max }$ and temperature of the combined data also presented no statistical significance.

As already represented in the standards, the same correction for temperature cannot be applied for heavy vehicles as for passenger cars. In ISO/DTS 13471-2 [21], a value of $-0.06 \mathrm{~dB} /{ }^{\circ} \mathrm{C}$ is proposed for correction based on air temperature, which is further reduced by $40 \%$ to $-0.036 \mathrm{~dB} /{ }^{\circ} \mathrm{C}$ for the $45-64 \mathrm{~km} / \mathrm{h}$ speed range to take into account the diluting effect of power-unit noise over tyre/road noise. This value is less than half of that of passenger cars. Even though the CPX method includes a tyre to represent heavy traffic, namely the AVON AV4, ISO/TS 13471-1:2017 [27] prescribes the same temperature correction as for the SRRT, representative of passenger car tyres. This indicates that the temperature influence of the Avon AV4 tyre may not be representative of the heavy vehicles measured during a SPB campaign. Additionally, there are concerns about whether the AVON AV4 is a suitable representative for the HM class of SPB [33]. In terms of literature, only one paper has reported a temperature correction for heavy traffic based on the SPB method specifically [29]. The authors of Ref. [29] also found no evidence for a temperature influence, although, as mentioned in the previous section, the data were collected during the night, which may not be comparable to the daytime measurements performed in this study. Other works have addressed the topic of temperature influence on road traffic noise levels for heavy vehicles using other methods such as CPX or CPB and air temperature. While these methods are valid tools for establishing a temperature correction for a specific tyre/road combination, their findings do not necessarily represent the temperature influence affecting SPB measurements. Nonetheless, as almost no literature is available on temperature influence within the SPB method, comparing the findings to this study is still relevant. A compilation of literature for heavy vehicles, based on CPX and pass-by methods is presented in Table 5.

Firstly, it is noted that the coefficients reported for the CPX method using the Avon AV4 tyre and the lab test are remarkably higher compared to the papers using pass-by methods. In more detail, the average of the reported temperature coefficients is $-0.091 \mathrm{~dB} /{ }^{\circ} \mathrm{C}$ for $\mathrm{CPX}$ and lab tests and $-0.023 \mathrm{~dB} /{ }^{\circ} \mathrm{C}$ for pass-by methods, which corresponds to a $75 \%$ difference. This confirms the earlier comment that the temperature influence on the Avon AV4 tyre is not representative for SPB measurements. However, another possible explanation for 
this discrepancy may be the diluting effect of power-unit noise only present in pass-by measurements. This may also be the reason for this study's lack of temperature influence for the HM category. Furthermore, even though the speed limit at all locations was $70 \mathrm{~km} / \mathrm{h}$, the mean speeds were substantially lower. For HM, the average speed was 53, 45 and $46 \mathrm{~km} / \mathrm{h}$ for locations 1, 2 and 3, respectively. The difference between the imposed speed limit and the mean speed is remarkable. Based on experience, it is expected that drivers decelerated upon noticing the SPB setup, believing that it might be a speed trap. While performing the measurement, the crew paid close attention to the vehicle speed; those that did not travel at a constant speed were discarded to ensure that the noise measurement was not affected by decelerating or accelerating. Regardless of these remarkable measurement speeds, the lower limit for the speed range in the standard is $45 \mathrm{~km} / \mathrm{h}$, so this study was within the requirements set. However, at these lower speeds, the overall vehicle noise of heavy vehicles is still dominated by power unit noise, as reported in [36] and as can be seen in Figure 5. The effect of temperature on power unit noise is more complex and vehicle dependent; as a result, the temperature-power-unit noise relation shows no clear trend within the scope of SPB measurements. It is expected that this dilution resulted in no apparent temperature influence on the total pass-by noise. In the standard, the diluting effect of power-unit noise over tyre/road noise reduces the temperature coefficient by $40 \%$. This reduction is only required at the speed range of $45-64 \mathrm{~km} / \mathrm{h}$, while no reduction should be applied at higher speeds. The results from this study indicate that the diluting effect of power-unit noise may be more significant than currently accounted for.

Table 5. Summary of temperature coefficients for heavy vehicles, calculated based on various methods as observed in the literature.

\begin{tabular}{|c|c|c|c|c|c|c|c|}
\hline Publication & $\begin{array}{c}\gamma_{\mathrm{U}, \mathrm{air}} \\
{\left[\mathrm{dB} /{ }^{\circ} \mathrm{C}\right]}\end{array}$ & $\mathbf{R}^{2}$ & Method & $\begin{array}{l}\text { Temp. } \\
\text { Range } \\
\text { Air/Road }\end{array}$ & $\begin{array}{l}\text { Pavement } \\
\text { Type }\end{array}$ & $\begin{array}{l}\text { Speed } \\
{[\mathrm{km} / \mathrm{h}]}\end{array}$ & Comment(s) \\
\hline $\begin{array}{l}\text { Sandberg } \\
\text { et al. [34] }\end{array}$ & -0.070 & / & $\begin{array}{l}\text { Test on } \\
\text { drums in } \\
\text { lab }\end{array}$ & $6-36 / 8-40$ & DAC & 50 & $\begin{array}{l}\text { - } \quad 2 \text { tyres tested } \\
\text { - } \quad \text { No radiation from the sun }\end{array}$ \\
\hline $\begin{array}{l}\text { Bühlmann } \\
\text { et al. [13] }\end{array}$ & -0.11 & / & $\begin{array}{l}\text { CPX: Avon } \\
\text { AV4 }\end{array}$ & $7-35 /-$ & DAC & $\begin{array}{l}50 \text { and } \\
80\end{array}$ & \\
\hline $\begin{array}{l}\text { Jabben } \\
\text { et al. [29] }\end{array}$ & 0 & / & SPB & $-6-19 /-$ & DAC & 70-100 & - $\quad$ During night \\
\hline $\begin{array}{l}\text { Mioduszewski } \\
\text { et al. [35] }\end{array}$ & -0.093 & 0.93 & $\begin{array}{l}\text { CPX: Avon } \\
\text { AV4 }\end{array}$ & $3-28 / 10-36$ & SMA & 50 & $\begin{array}{l}\text { The authors cite the } \\
\text { Sperenberg Project, but the } \\
\text { original source was } \\
\text { not found. }\end{array}$ \\
\hline $\begin{array}{l}\text { Bentsen } \\
\text { et al. [19] }\end{array}$ & -0.048 & / & $\mathrm{CPB}$ & $0-35$ & Dense & 70 & \\
\hline U.S.DoT [31] & -0.02 & / & $\begin{array}{l}\text { Pass-by at } \\
15 \mathrm{~m}\end{array}$ & & DAC & / & $\begin{array}{l}\text { Greater distance }(15 \mathrm{~m}) \\
\text { between road and } \\
\text { microphone } \\
\text { - Calculated as the average of } \\
\text { different temperature } \\
\text { coefficients of which some } \\
\text { were showed low } \mathrm{R}^{2}\end{array}$ \\
\hline
\end{tabular}




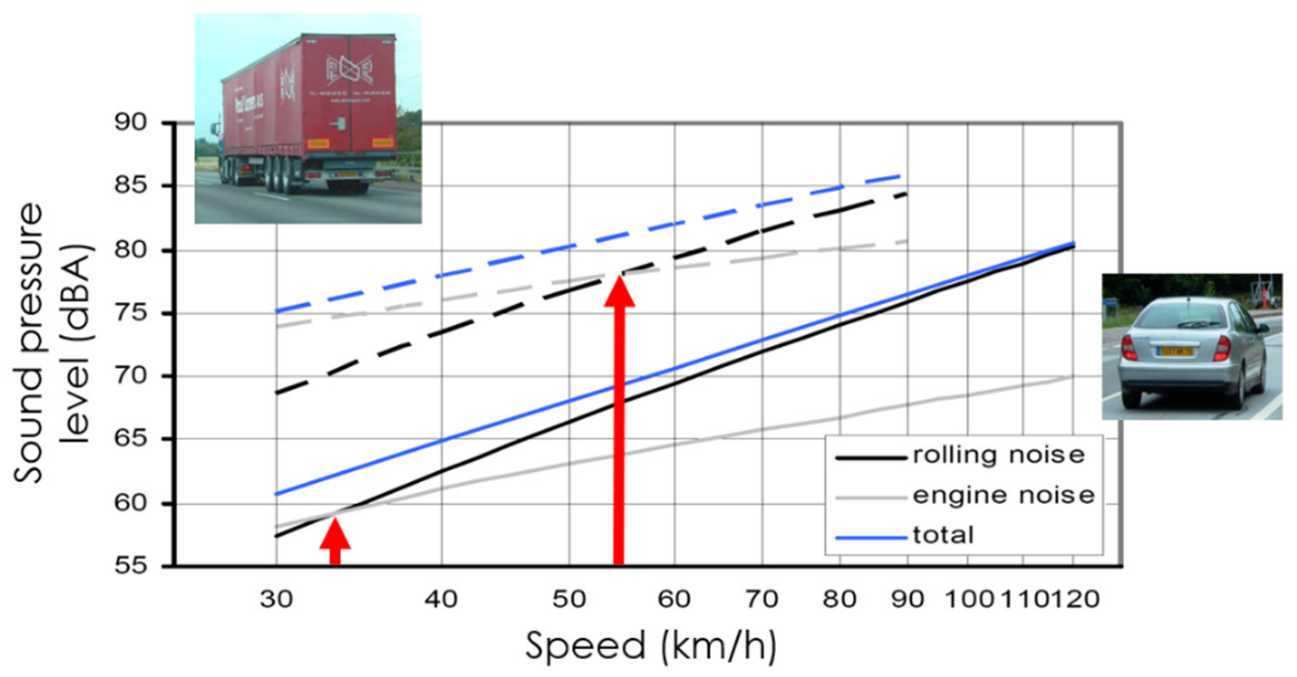

Figure 5. Share of tyre/road and power unit noise (based on data from [36]).

\subsubsection{Choice of Temperature}

The temperature coefficients were calculated in previous sections based on air temperature as it is most commonly used in standardisation methods and literature. Nevertheless, the choice of temperature (air, road, or tyre) remains a relevant discussion for multiple reasons, as mentioned in Section 2.4. Firstly, tyre temperature is most closely related to how temperature influences tyre/road noise [23]; yet it is impossible to measure in the context of SPB measurements. Alternatively, air and road temperature indirectly affect road traffic noise levels, but it is unclear if one is better suited for correction procedures.

In this study, air and road temperatures show a strong correlation, with an $R^{2}$ of 0.856 considering all data from all locations. The correlations improve slightly when considering individual locations $(0.86-0.91)$. This is in line with previous studies $[17,24,31]$. This strong correlation indicates that no major differences in correction accuracy between the temperatures are to be expected. To further investigate this, the correlation strength between $L_{\mathrm{A}, \max }$ and temperature, indicated by the $\mathrm{R}^{2}$, is compared for air and road temperature. Since vehicle category $\mathrm{P}$ presented good correlations for all locations, we chose to further analyse the different temperature types by using the results from this category (Figure 6). Moreover, the $\mathrm{R}^{2}$ values of passenger cars are better or similar to other studies $[17,24]$. Due to methodological differences, a direct comparison between studies is difficult, but the similarities in values indicate that the data and method used in this study are adequate. From Figure 6, it is concluded that the air temperature appears to be better suited for use in a temperature correction than road temperature as it showed a higher average $\mathrm{R}^{2}$ value. Aside from the correlation strength, a comparison of the results for air and road temperature shows that the magnitude of temperature coefficients is larger for air temperature than road temperature. This is simply because the road temperature varies much more than the air temperature. The ratio of temperature coefficient for air to road is, on average, 1.30 for vehicle category $\mathrm{P}$, which matches the slope of the regression line between air and road temperature (=1.28). Lastly, in their study, Bühlmann et al. [23] proposed an equation, see Equation (3), to estimate the tyre temperature when it is not possible to measure it directly, as is the case with the SPB method. The estimated tyre temperature was added to the analysis but did not show an improvement in $R^{2}$ values. 


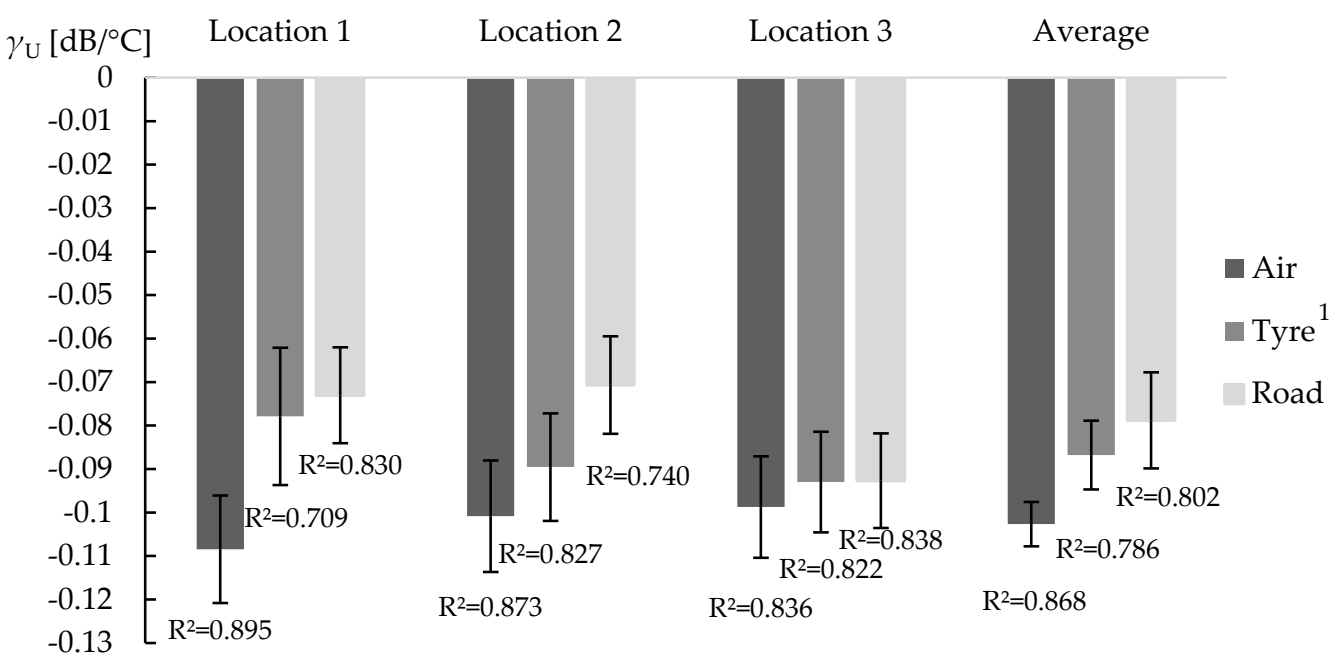

Figure 6. Comparison of different temperature coefficients $\gamma_{U}$ at the different locations and averaged. ${ }^{1}$ Estimated tyre temperature calculated per Equation (3) [23] using the air and road temperatures.

\subsubsection{Temperature Coefficient in Third-Octave Bands}

Concerning a temperature correction on the noise levels of individual (third-) octave bands, all of the major standards apply the same correction for the individual (third-) octave bands as for the overall $L_{\mathrm{A}, \max }$. Yet, as the noise generation mechanisms work in different (third-)octave bands and are likely to be affected differently, a homogeneous correction may therefore be unrealistic. In this study, an attempt was made to determine the influence on $L_{\mathrm{A}, \max }$ in third-octave bands. As described in Section 2.3.1, two sonometers were used due to limitations in the main set-up to register the $L_{\mathrm{A}, \max }$ in 1/3-octave bands. Some data were lost during the correlation between sonometers, resulting in only category $\mathrm{P}$ at location 1 consisting of sufficient data for the analysis in third-octave bands. Based on the average spectrum of the pass-bys, a range of $50-10,000 \mathrm{~Hz}$ was selected to be relevant for traffic noise. The $p$-values for temperature influence in the $50-10,000 \mathrm{~Hz}$ range are plotted in Figure 7.

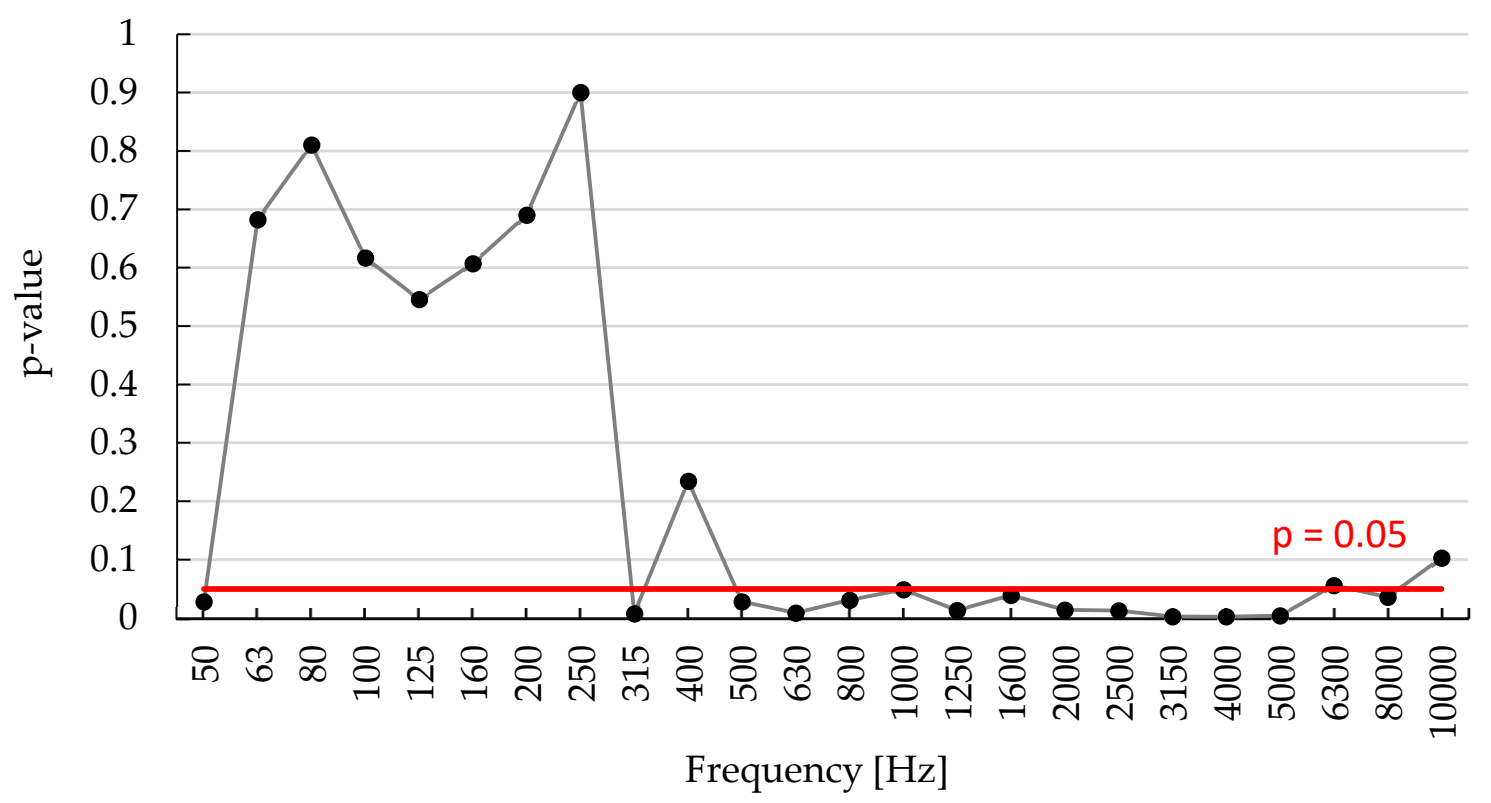

Figure 7. $p$-values from the analysis on the temperature coefficients on third-octave bands across the 50-10,000 Hz range. 
The $p$-values at the low-frequency bands $(<315 \mathrm{~Hz})$ show no statistical significance at a significance level of $5 \%$, indicating that temperature may not influence the $L_{\mathrm{A}, \max }$ in these bands. These findings differ from Ref. [17] and Ref. [24], where contradicting, but significant temperature coefficients were found in this region of the spectrum. Where Anfosso-Lédée et al. [17] found large negative temperature coefficients, Sánchez-Fernández et al. [24] reported moderate positive values. The methods used in these studies are similar to that of this study: $\mathrm{CPB}$ and continuous flow measurement, respectively. Additionally, all studies considered dense asphalt surfaces. The difference in findings is possibly due to variation in traffic, especially in the study of Ref. [17], which only considered two tyres. Another explanation may be that power-unit noise is dominant in these specific frequency bands. In the middle and high-frequency bands $(315-8000 \mathrm{~Hz})$, the $p$-values in Figure 7 are below the $5 \%$ significance level for all octave bands, except for 400 and $6300 \mathrm{~Hz}$.

Figure 8 shows, in the left-hand side y-axis, the temperature coefficients in the $50-10,000 \mathrm{~Hz}$ range; the octave bands presenting $R^{2}$ values larger than 0.70 received a green marker while the others are coloured in red. All frequency bands in the $315-8000 \mathrm{~Hz}$ reported $R^{2}$ values larger than 0.70 , except for the 400, 1000, 1600 and $6300 \mathrm{~Hz}$ bands. The calculated temperature coefficients vary from -0.099 to $-0.144 \mathrm{~dB} /{ }^{\circ} \mathrm{C}$, but no clear spectral dependence is observed. These negative values are consistent with Refs. [17,24], although the first study did not present significant p-values in this range. At $1600-2000 \mathrm{~Hz}$, both these authors reported a reduction in the temperature correction, reaching the lowest values; this trend is not apparent in Figure 8. Temperature influence in these frequency bands was also investigated by Bühlmann et al. [28] using the CPX method, but limited to the SRTT tyre. These authors observed a smaller influence of temperature on SPL at the middle frequencies $(315-2000 \mathrm{~Hz})$, while from $2500-5000 \mathrm{~Hz}$, the temperature coefficient presented increasingly negative values.

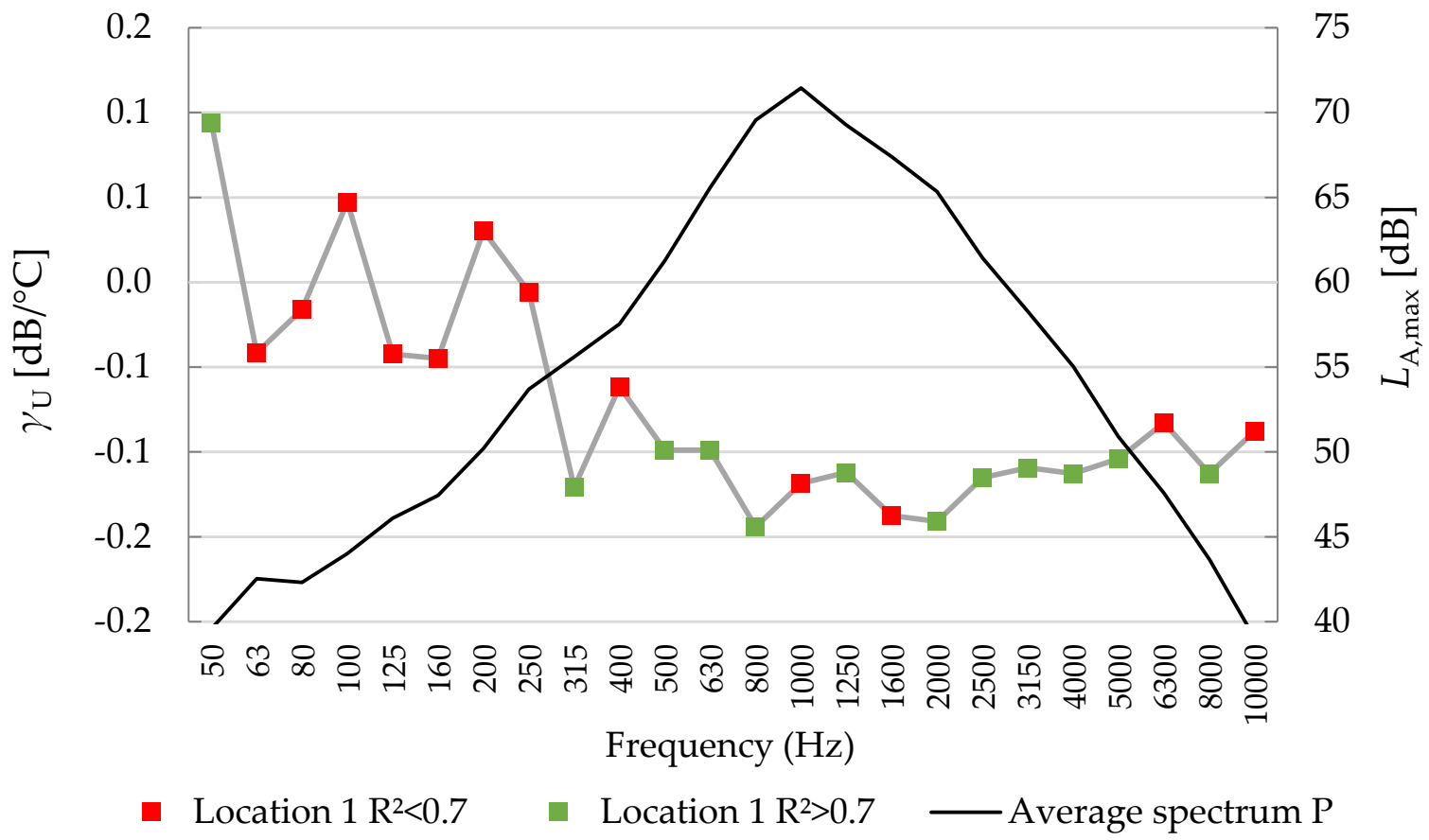

Figure 8. Temperature coefficients for passenger cars in third-octave bands $(50-10,000 \mathrm{~Hz})$ and averaged spectrum of all passenger car pass-bys at location 1 .

\subsection{CPX Results}

In addition to the SPB results, a CPX measurement was performed at the three sites. The goal was to evaluate the acoustic properties of the pavements at the locations by a different method and validate the selected SPB measurement locations. During the CPX measurement, the air temperature was very close to the reference temperature at $20 \pm 1{ }^{\circ} \mathrm{C}$, 
while the road surface temperature ranged from 28 to $31^{\circ} \mathrm{C}$, and was performed at the reference speed of $50 \mathrm{~km} / \mathrm{h}$. A section of $200 \mathrm{~m}$ was measured at each location while reporting the $L_{\mathrm{CPX}: \mathrm{P}}$ values for $20 \mathrm{~m}$ segments. The CPX results were similar across the locations: location 1 and 3 shared the same $L_{\mathrm{CPX}: P}$ result, while location 2 had an average of only $0.2 \mathrm{~dB}$ lower than the other two, as shown in Table 6 . The standard deviation on the

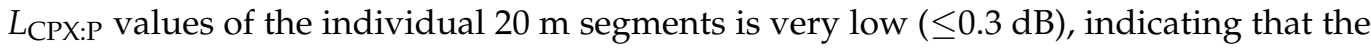
acoustic properties of the road section were homogeneous over the entire length and that the selected SPB measurement locations are representative of the whole section.

Table 6. Overview of $L_{\mathrm{CPX}: \mathrm{P}}, L_{\mathrm{SPB}: \mathrm{P}, 50}$ and predicted $L_{\mathrm{SPB}: \mathrm{P}, 50}$ for the three locations.

\begin{tabular}{cccc}
\hline Location & $L_{\text {CPX:P }}[\mathrm{dB}]$ & $L_{\text {SPB:P,50 }}[\mathrm{dB}]$ & Predicted $L_{\text {SPB:P,50 }}[\mathrm{dB}]$ \\
\hline Location 1 & $92.8 \pm 0.1$ & 74.3 & 72.6 \\
Location 2 & $92.6 \pm 0.1$ & 73.8 & 72.4 \\
Location 3 & $92.8 \pm 0.3$ & 74.4 & 72.6 \\
\hline
\end{tabular}

Figure 9 depicts the $L_{\mathrm{CPX}: \mathrm{P}}$ values and the average spectrum for vehicle category $\mathrm{P}$ in one-third octave bands for location 1, clearly following the same trend. In the ROSANNE project [37], the relation between $L_{\mathrm{CPX}: \mathrm{P}}$ and SPB measurements was analysed, leading to Equation (5):

$$
L_{\mathrm{SPB}: \mathrm{P}}=0.95 L_{\mathrm{CPX}: \mathrm{P}}-15.6 \mathrm{~dB}
$$

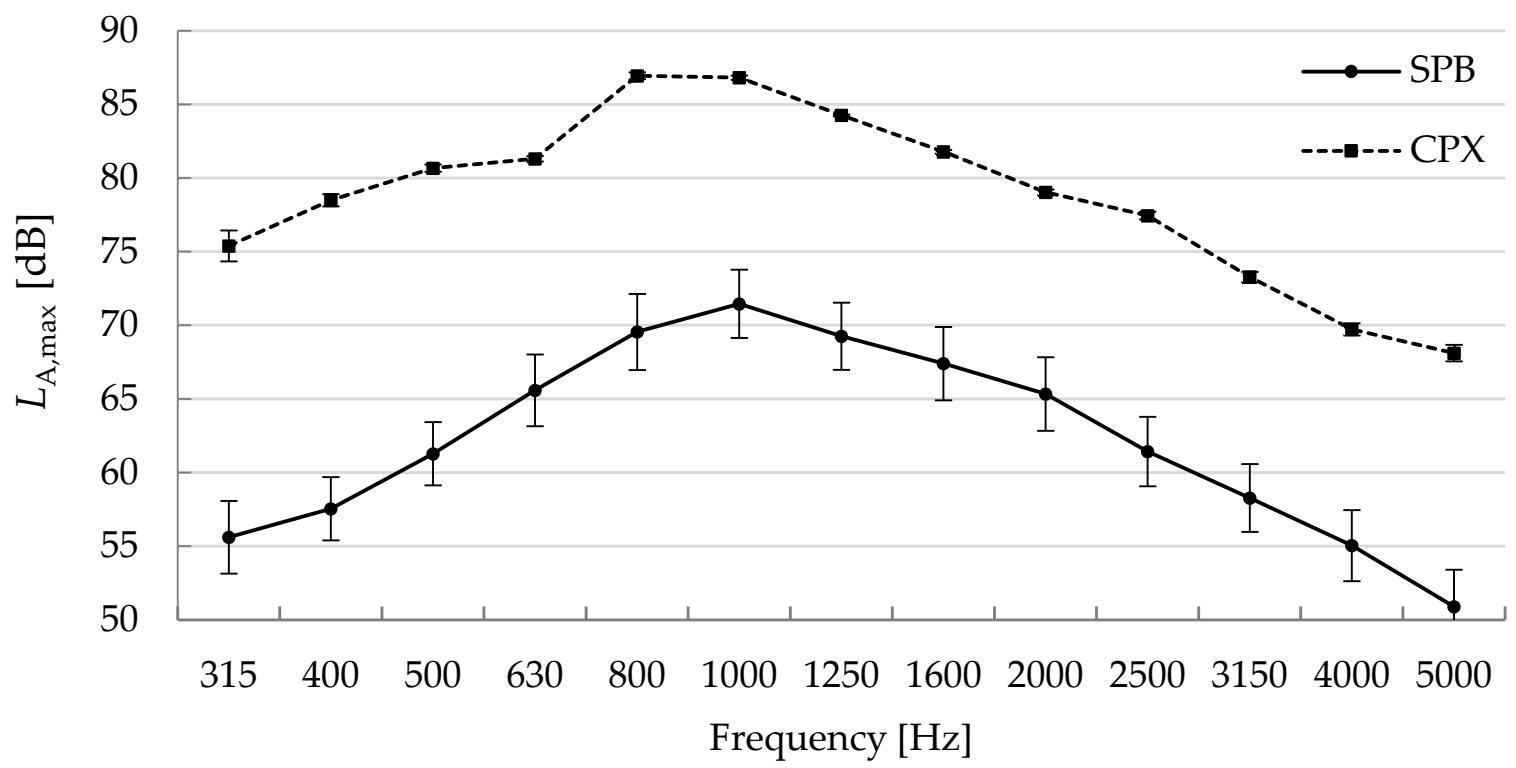

Figure 9. $L_{\mathrm{CPX}: \mathrm{P}}$ and averaged spectrum of pass-by passenger cars for the $315-5000 \mathrm{~Hz}$.

Equation (5) was applied to the $L_{\mathrm{CPX}: P}$ values from this study, leading to predicted $L_{S P B}: P, 50$ values included in Table 6 . The predicted $L_{S P B: P, 50}$ deviate from the actual $L_{S P B: P, 50}$ results by 1.4 to $1.8 \mathrm{~dB}$. In the referenced study $90 \%$ of the predicted $L_{S P B} P, 50$ were within

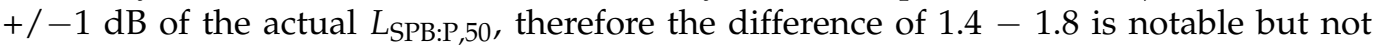
alarming, especially considering the empirical nature of the Equation (5).

\section{Conclusions}

This study investigated the influence of temperature on road-traffic noise by means of the statistical pass-by method according to ISO/DIS 11819-1 [20]. In total, 5716 pass-by vehicles captured (2896 of P, 295 of HD and 2525 of HM) at three locations with either an asphalt concrete or SMA pavement. The measurements were performed over a 7-month period, covering the complete temperature range described in ISO/DIS 11819-1. The data from different measurements at the same location were combined and a new statistics-based 
procedure was applied to deal with the large spread of data inherent to the SPB method. Additionally, CPX measurements were performed at the three locations to evaluate the acoustic properties and validate that the pavement sections at the microphone location during the SPB measurements were representative of the whole road. The key findings are:

- The air-temperature coefficients for passenger cars on AC and SMA pavements are similar. The result from this study, an average air temperature coefficient of $-0.103 \mathrm{~dB} /{ }^{\circ} \mathrm{C}$ for passenger cars, supports the procedure in ISO/DTS 13471-2.

- No statistical evidence was found for temperature influence on road traffic noise concerning heavy vehicles. This is expected because of the low speed $(45-53 \mathrm{~km} / \mathrm{h})$ during the measurements. At these speeds, the power unit noise dilutes the tyre/road noise. The effect of temperature on power unit noise is very complex and vehicle-dependent; as a result, there is no clear trend for this effect in terms of SPB measurements. Therefore, the temperature influence on the overall noise level is not (statistically) noticeable. While the diluting effect is accounted for in the standard by a reduction in the temperature coefficient of $40 \%$ in the speed range of $45-64 \mathrm{~km} / \mathrm{h}$, in this study the diluting effect appears to be higher, which may indicate that the diluting effect is underestimated and the reduction should be increased further.

- In this study, both air and road temperatures were considered. The $\mathrm{R}^{2}$ values of the linear regression obtained from the $L_{\mathrm{A}, \max }$-temperature correlation were consistently the highest for air temperature, although the differences from the $\mathrm{R}^{2}$ of road temperature were small. This indicates that air temperature holds a marginal benefit over road temperature for correction procedures. Tyre temperature, estimated using a formula by Bühlmann et al. [23], did not show an improvement over the other temperatures.

- An analysis of temperature coefficients in one-third-octave bands for passenger cars showed no temperature influence at the low-frequency range $(<315 \mathrm{~Hz})$, contradicting previous research. A temperature influence at the middle and high frequencies $(315-10,000 \mathrm{~Hz})$ was statistically proven. Unexpectedly, the temperature coefficients in this range are considerably unvarying, and thus are not spectral dependent, ranging between -0.10 and $-0.15 \mathrm{~dB} /{ }^{\circ} \mathrm{C}$.

This study succeeded in achieving its original goal of verifying the temperature correction for road-traffic noise of passenger cars. Although the measurements were performed using the SPB method according to ISO/DIS 11819-1 [20], the findings from this study are also relevant for other methods such as continuous flow measurements and noise mapping. More research is needed for heavy vehicles, however. More specifically, the temperature influence on road-traffic noise should be investigated at higher speeds for this vehicle category. Additionally, the analysis of the temperature influence on the noise levels in third-octave bands, here limited to passenger cars, can be applied to heavy vehicles in future research. Even though this study assessed AC and SMA pavements, the literature still lacks research on temperature influence using the SPB method for porous pavements and cement concrete pavements. In future research, the authors intend to use this extensive SPB dataset to analyse changes made in ISO/DIS 11819-1 [20] compared to the old version [11] especially concerning the $L_{\mathrm{A}, \max }$ difference between vehicle categories $\mathrm{HD}$ and HM, the proposed speed coefficients for the heavy category and the relation between the number of axles and $L_{\mathrm{A}, \max }$ in the heavy category.

Author Contributions: Conceptualisation, L.G.; methodology, C.V. and L.G.; software, A.G.d.B. and M.G.; formal analysis, M.G. and A.G.d.B.; investigation, M.G.; resources, C.V. and L.G.; writingoriginal draft preparation, M.G., A.G.d.B., C.V. and L.G.; writing-review and editing, M.G., A.G.d.B., C.V. and L.G; visualisation, M.G. and A.G.d.B.; supervision, C.V. and L.G.; funding acquisition, C.V. and L.G. All authors have read and agreed to the published version of the manuscript.

Funding: The authors want to thank the faculty of Applied Engineering at the University of Antwerp for funding the PhD of Ablenya Grangeiro de Barros. 
Data Availability Statement: The data presented in this study are available on request from the corresponding author. The data are not publicly available due to plans to submit a second paper, after which the data will be made publicly available.

Acknowledgments: The authors would like to thank the assistance of Anneleen Bergiers, from BRRC, for providing relevant materials for the construction of this paper. This work would not have been completed without the technical support from the technicians and researchers from BBRC who performed the CPX measurements and provided the equipment and necessary explanations for the SPB measurements. Lastly, we thank the former Master's students Dario Regnier and Nathan Muts for their assistance during the SPB measurements.

Conflicts of Interest: The authors declare no conflict of interest.

\section{References}

1. Havard, S.; Reich, B.J.; Bean, K.; Chaix, B. Social inequalities in residential exposure to road traffic noise: An environmental justice analysis based on the RECORD Cohort Study. Occup. Environ. Med. 2011, 68, 366-374. [CrossRef] [PubMed]

2. WHO. Environmental Noise Guideline for the European Region; WHO: Copenhagen, Denmark, 2018.

3. Kempen, E.; Casas, M.; Pershagen, G.; Foraster, M. WHO Environmental Noise Guidelines for the European Region: A Systematic Review on Environmental Noise and Cardiovascular and Metabolic Effects: A Summary. Int. J. Environ. Res. Public Health 2018, 15, 379. [CrossRef] [PubMed]

4. Basner, M.; McGuire, S. WHO Environmental Noise Guidelines for the European Region: A Systematic Review on Environmental Noise and Effects on Sleep. Int. J. Environ. Res. Public Health 2018, 15, 519. [CrossRef] [PubMed]

5. Clark, C.; Paunovic, K. WHO Environmental Noise Guidelines for the European Region: A Systematic Review on Environmental Noise and Quality of Life, Wellbeing and Mental Health. Int. J. Environ. Res. Public Health 2018, 15, 2400. [CrossRef] [PubMed]

6. Parris, K.M.; Schneider, A. Impacts of Traffic Noise and Traffic Volume on Birds of Roadside Habitats. Ecol. Soc. 2009, 14, 29. [CrossRef]

7. Capros, P.; De Vita, A.; Tasios, N.; Siskos, P.; Kannavou, M.; Petropoulos, A.; Evangelopoulou, S.; Zampara, M.; Papadopoulos, D.; Nakos, C.; et al. EU Reference Scenario 2016: Energy, Transport and GHG Emissions: Trends to 2050; Publications Office: Luxembourg, 2016. [CrossRef]

8. Regulation No 117 of the Economic Commission for Europe of the United Nations (UNECE)-Uniform provisions concerning the approval of tyres with regard to rolling sound emissions and/or to adhesion on wet surfaces and/or to rolling resistance [2016/1350]. Off. J. Eur. Union 2016, L 218, 1-106.

9. EN ISO 13325:2019; Tyres-Coast-by Methods for Measurement of Tyre-to-Road Sound Emission. The International Organization for Standardization: Geneva, Switzerland, 1997.

10. EN ISO 11819-2:2017; Acoustics-Measurement of the Influence of Road Surfaces on Traffic Noise-Part 2: The Close-Proximity Method. The International Organization for Standardization: Geneva, Switzerland, 2017.

11. EN ISO 11819-1:1997; Acoustics-Measurement of the Influence of Road Surfaces on Traffic Noise-Part 1: Statistical Pass-By Method. The International Organization for Standardization: Geneva, Switzerland, 1997.

12. T 360-16; Standard Method of Test for Measurement of Tire/Pavement Noise Using the On-Board Sound Intensity OBSI Method. AASHTO: Washington, DC, USA, 2020.

13. Bühlmann, E.; Ziegler, T. Temperature effects on tyre/road noise measurements. In Proceedings of the InterNoise 2011, Osaka, Japan, 4-7 September 2011.

14. Sandberg, U.; Ejsmont, J.A. Tyre/Road Noise Reference Book; INFORMEX: Kisa/Harg, Sweden, 2002; ISBN 9789163126109/9163126109.

15. Rasmussen, R.O.; Bernhard, J.R.; Sandberg, U.; Mun, E.P. The Little Book of Quieter Pavements, 1st ed.; Federal Highway Administration: Washington, DC, USA, 2007.

16. Ling, S.; Yu, F.; Sun, D.; Sun, G. A comprehensive review of tire-pavement noise: Generation mechanism, measurement methods, and quiet asphalt pavement. J. Clean. Prod. 2021, 287, 125056. [CrossRef]

17. Anfosso-Lédée, F.; Pichaud, Y. Temperature effect on tyre-road noise. Appl Acoust. 2007, 68, 1-16. [CrossRef]

18. Hamet, J.F.; Klein, P. Road Stiffness Influence on Rolling Noise: Parametric Study Using a Rolling Tire Model. SILVIA-INRETS008-WP2, 2004. Available online: https:/ / hal.archives-ouvertes.fr/hal-00546101/document (accessed on 10 January 2022).

19. Bendtsen, H.; Lu, Q.; Kohler, E. Temperature Influence on Road Traffic Noise: Californian OBSI Measurement Study; UCPRC-RP2010-02; The Danish Road Institute-Road Directorate and University of California Pavement Research Center. 2010. Available online: http:/ / www.ucprc.ucdavis.edu/pdf/UCPRC-RP-2010-02.pdf (accessed on 10 January 2022).

20. EN ISO/DIS 11819-1:2021; EN ISO. Acoustics-Measurement of the Influence of Road Surfaces on Traffic Noise-Part 1: Statistical Pass-By Method. The International Organization for Standardization: Geneva, Switzerland, 2021.

21. EN ISO/DTS 13471-2; Acoustics-Temperature Influence on Tyre/Road Noise Measurement—Part 2: Correction for Temperature When Testing with the Pass-By Methods. The International Organization for Standardization: Geneva, Switzerland, 2021.

22. Bühlmann, E.; Ziegler, T. Temperature effects on tyre/road noise measurements and the main reasons for their variation. In Proceedings of the InterNoise 2013, Innsbruck, Austria, 15-18 September 2013. 
23. Bühlmann, E.; Schlatter, F.; Sandberg, U. Temperature influence on tire/road noise measurements: Recently collected data and discussion of various issues related to standard testing procedures. In Proceedings of the InterNoise 2021, Washington, DC, USA, 1-5 August 2021; pp. 1380-1395. [CrossRef]

24. Sánchez-Fernández, M.; Barrigón Morillas, J.M.; Montes González, D.; Rey Gozalo, G. Relationship between temperature and road traffic noise under actual conditions of continuous vehicle flow. Transp. Res. D 2021, 100, 103056. [CrossRef]

25. Bendtsen, H.; Lu, Q.; Kohler, E. Acoustic Aging of Asphalt Pavements: A Californian/Danish Comparison. Report: UCPRC-RP2010-01. The Danish Road Institute-Road Directorate and University of California Pavement Research Center. 2010. Available online: http:/ / www.ucprc.ucdavis.edu/pdf/UCPRC-RP-2010-01.pdf (accessed on 10 January 2022).

26. Vieira, T.; Sandberg, U. Temperature Effects on Tyre/Road Noise Measurements; Project Report R3.1; CEDR Transnational Road Research Programme Call 2018; Noise and Nuisance: London, UK, 2021.

27. ISO/TS 13471-1:2017; EN ISO. Acoustics-Temperature Influence on Tyre/Road Noise Measurement-Part 1: Correction for Temperature When Testing with the CPX Method. The International Organization for Standardization: Geneva, Switzerland, 2021.

28. Bühlmann, E.; Sandberg, U.; Mioduszewski, P. Speed dependency of temperature effects on road traffic noise. In Proceedings of the Internoise 2015, San Francisco, CA, USA, 9-12 August 2015.

29. Jabben, J.; Potma, C. Temperature Effects on Road Traffic Noise Measurements. J. Appl. Phys. 2013, 2, $43-46$.

30. Landsberger, B.J.; DeMoss, J.; McNerney, M. Effects of Air and Road Surface Temperature on Tire Pavement Noise on an ISO 10844 Surface. In Proceedings of the 2001 Noise and Vibration Conference, Traverse City, MI, USA, 30 April-3 May 2001.

31. United States Department of Transportation. Investigation of Temperature Correction for Tire/Pavement Noise Measurements; Federal Highway Administration: Washington, DC, USA, 2010. Available online: https://rosap.ntl.bts.gov/view/dot/9338/dot_9338 _DS1.pdf (accessed on 10 January 2022).

32. Yuan, M.; Ni, D.; Zhang, D.; Wei, X.; Wang, Z.; Wang, C. Effect of temperature on road pass-by noise of light vehicle. IOP Conf. Ser. Earth Environ. Sci. 2019, 310, 022003. [CrossRef]

33. Jackett, R. Task A: Close Proximity versus Wayside Measurements; 5-27854.00 TASKA; NZTA Road Surface Noise Research Programme: Wellington, New Zealand, 2019.

34. Sandberg, U.; Mioduszewski, P. Deliverable D2.2: Measurement Methods for the Noise Emission Properties of Road Surfaces; Rosanne Project, 2015. Available online: https:/ / www.rosanne-project.eu/ajax/DownloadHandlerFM.php/downloadFile?id=11 820 (accessed on 10 January 2022).

35. Mioduszewski, P.; Taryma, S.; Woźniak, R. Temperature influence on tyre/road noise of selected tyres. In Proceedings of the InterNoise 2014, Melbourne, Australia, 16-19 November 2014.

36. van Keulen, W. The Numerical Effects of Non-Low Noise Roadtypes on Roundabouts Revisited. In Proceedings of the 20th International Congress on Sound and Vibration, Bangkok, Thailand, 7-11 July 2013.

37. Kragh, J.; Holck Skov, R.S.; Oddershede, J.; Anfosso-Lédée, F.; Bartolomaeus, W.; Zöller, M.; Berge, T.; Bergiers, A.; Muirhead, M.; Werh, R. Deliverable D2.3: Report on the Analysis and Comparison of Existing Noise Measurement Methods for Noise Properties of Road Surfaces; Rosanne Project, 2015. Available online: https:/ / www.rosanne-project.eu/ajax/DownloadHandlerFM.php/ downloadFile?id=11821 (accessed on 10 January 2022). 